\title{
UNA NUEVA ESPECIE DE RIBES (GROSSULARIACEAE) DE MICHOACÁN, MÉXICO
}

\author{
Carlos M. Durán-Espinosa \\ e-mail: duranc@ecologia.edu.mx \\ Y \\ Sergio Avendaño Reyes \\ e-mail: avenda@ecologia.edu.mx \\ Instituto de Ecología, A.C. \\ Departamento de Sistemática Vegetal \\ Apartado postal 63 \\ 91000 Xalapa, Veracruz
}

\begin{abstract}
RESUMEN
Se propone como especie nueva para la ciencia a Ribes grandisepalum, un arbusto que habita en el bosque de Abies en el estado de Michoacán, México. Este taxon pertenece al subgénero Coreosma sección Calobotrya (Spach) Jancz. (Grossulariaceae) y se encuentra estrechamente relacionado con Ribes pringlei Rose. Se distingue de éste por presentar sépalos glandulosopubescentes, que alcanzan tamaños de 5.5-8.5 mm de largo, pedicelos de 7-17 $\mathrm{mm}$ de largo y pelos glandulares en el ovario y el fruto.

Palabras clave: Grossulariaceae, México, Michoacán, Ribes.

\section{ABSTRACT}

Ribes grandisepalum, a shrub that lives in the forest of Abies in the state of Michoacan, Mexico, is proposed as a new species to science. The new taxon belongs to subgenus Coreosma section Calobotrya (Spach) Jancz. (Grossulariaceae) and is related to Ribes pringlei Rose. It is distinguished by its glandular-pubescent sepals that reach sizes of $5.5-8.5 \mathrm{~mm}$ in length, pedicels 7-17 $\mathrm{mm}$ in length and the ovary and fruit with glandular hairs.
\end{abstract}

Key words: Grossulariaceae, Mexico, Michoacan, Ribes.

Al examinar ejemplares del género Ribes para la Flora de Veracruz (DuránEspinosa, 2001), se detectaron especímenes determinados originalmente como $R$. ciliatum, cuyas características con respecto al tamaño de los sépalos y pedicelos, así como al indumento de los frutos, no correspondían a dicha especie (Cuadro 1). Por tal motivo, se realizó una revisión exhaustiva de los taxa de este género descritos para México y se llegó a la conclusión de que se trata de una especie nueva. 
Ribes L. (Grossulariaceae) es un género cosmopolita con cerca de 150 taxa (Sinnott, 1985), incluye diversas especies cultivadas por sus frutos comestibles, conocidos como grosellas. La mayoría se encuentra en el hemisferio norte, aunque para la región de los Andes se han registrado 35. La delimitación de Ribes es controversial, debido a que en este género se reconocen dos grupos: el que incluye plantas espinescentes con unos cuantos racimos de flores escasas (uva-espinas) y el constituido por taxa carentes de espinas con racimos de numerosas flores (grosellas). Tales conjuntos son reconocidos indistintamente como dos géneros: Grossularia y Ribes (Sponberg, 1972); o bien, dentro de Ribes como subgéneros (Coville y Briton 1908; Berger, 1924; Poyarkova 1939; Sinnott 1985). Con estudios recientes sobre filogenias moleculares se han detectado también dos grupos (Messinger et al., 1999); sin embargo, no existe consenso en la circunscripción de los mismos.

Ribes grandisepalum C. Durán-Espinosa \& S. Avendaño, sp. nov. Fig. 1.

Frutex ad $4 \mathrm{~m}$ altus; folia 2-6.5 cm longa et lata, palmata, 3-5 lobata, alternatim disposita; inflorescentiae $3.5-7 \mathrm{~cm}$ longae, racemosae, glanduloso-pubescentes, pedicelli 7-17 mm longi, basaliter bracteati, bracteae 7-26.5 mm longae, lanceolatae vel foliaceae; flores albidi vel subrosei; hypanthium 6.5-10 mm longum, 4.5-8.5 mm latum, tubulosum; sepala 5.5-8.5 mm longa, extus glanduloso-pubescentia, petala $3.8 \mathrm{~mm}$ longa, glabra; stamina linearia, filamenta 4.3-5 mm longa, antherae oblongae, basifixae; ovarium 4.5-6 mm longum, inferum, pyriforme, glandulosum; stylus $10.5 \mathrm{~mm}$ longus, furcatus ad apicem; fructus 8.3-9 mm longi, 5.2-5.5 mm lati, baccati, rubelli vel purpurati, glandulosi; semina ellipsoidea, numerosa.

Arbusto de 2.5-4 m de alto, sin espinas, con la corteza fisurada, las ramas cuando adultas escasamente glanduloso-pubescentes o glabras. Hojas alternas, pecioladas, palmadamente lobadas, de 2-6.5 cm de largo, 2-6.5 cm de ancho, con 3-5 lóbulos agudos, cuando presentan 5 lóbulos, los 2 basales más pequeños que los 2 intermedios y el apical, el lóbulo apical tan grande como los lóbulos intermedios o frecuentemente duplicando su tamaño, margen irregularmente dentado, glanduloso-pubescente, ápice agudo, base subcordada, senos abiertos, superficie adaxial con pelos glandulares esparcidos, la abaxial glanduloso-pubescente sobre todo a lo largo de las venas, la venación actinódroma marginal, sumergida en el haz, sobresaliente en el envés, pecíolo de 1.5-4 cm de largo, 0.4-0.8 mm de ancho, glanduloso-pubescente, base dilatada, envainante, con pelos glandulares hasta de $1.5 \mathrm{~mm}$ de largo. Inflorescencia racemosa, de ca. 12 flores, de $3.5-7 \mathrm{~cm}$ de largo, glanduloso-pubescente, pedúnculo de $3-4.3 \mathrm{~cm}$ de largo, 0.9-1.1 $\mathrm{mm}$ de ancho. Flores blanquecinas a rosadas, pedicelos de 7-17 mm de largo, 0.4-0.5 mm de ancho, glanduloso-pubescentes, brácteas lanceoladas a foliáceas, ápice acuminado, sésiles, de 7-26.5 mm de largo, 2-7.5 mm de ancho, glanduloso-pubescentes, bracteolas lanceoladas, ápice acuminado, sésiles, de 2.5-6 mm de largo, 0.3-0.8 mm de ancho, glanduloso-pubescentes; hipantio tubular, de 6.5-10 mm de largo, 4.5-8.5 mm de ancho, glanduloso-pubescente; sépalos 5, oblongos, de 5.5$8.5 \mathrm{~mm}$ de largo, 2.2-2.8 mm de ancho, dorsalmente glanduloso-pubescentes, ventralmente glabros; pétalos 5, orbiculares, de $3.8 \mathrm{~mm}$ de largo, $3.5 \mathrm{~mm}$ de ancho, glabros, alternando con los sépalos; estambres 5, lineares, incluidos, filamentos de $4.3-5 \mathrm{~mm}$ de largo, 0.2- 


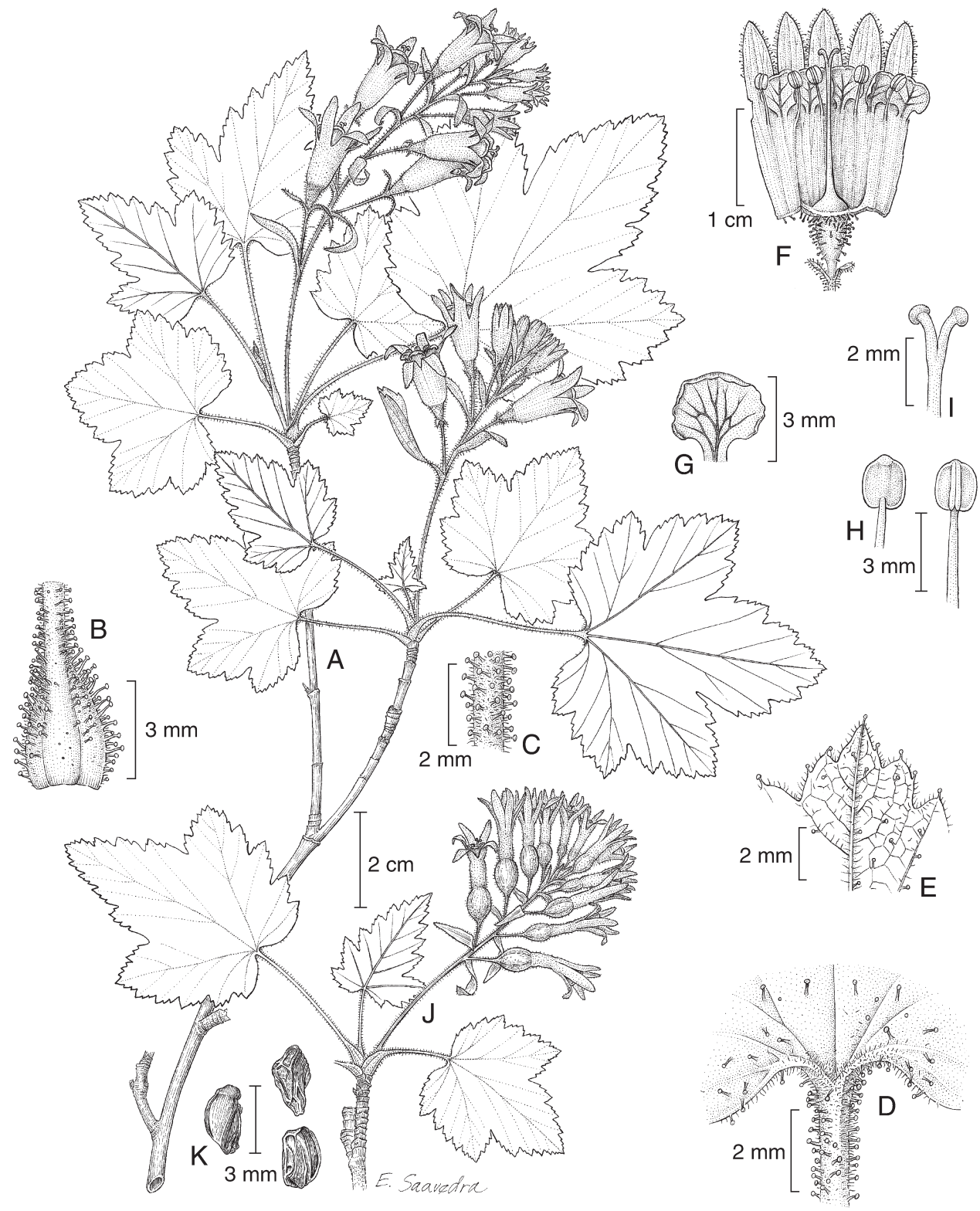

Fig. 1. Ribes grandisepalum. A. rama con inflorescencia; B. base del pecíolo de la hoja; C. fragmento de pecíolo; D. base de la hoja; E. superficie adaxial de la hoja; F. flor abierta; G. pétalo; H. estambres; I. estilo; J. rama con infrutescencia. Ilustración de E. Saavedra basada en el ejemplar de Rzedowski 46282. 
$0.3 \mathrm{~mm}$ de ancho, insertos internamente a la superficie de la copa floral por arriba de la mitad, alternando con los pétalos, anteras oblongas, de 1.3-1.6 mm de largo, 0.7-0.8 mm de ancho, basifijas, la dehiscencia longitudinal; ovario ínfero, piriforme, de $4.5-6 \mathrm{~mm}$ de largo, $3 \mathrm{~mm}$ de ancho, glandular, estilo de $10.5 \mathrm{~mm}$ de largo, 0.4-0.7 mm de ancho, bifurcado apicalmente, estigmas truncados. Fruto una baya, de color rojo a guinda, ovoide, de 8.3-9 mm de largo, 5.2-5.5 mm de ancho, glandular, con vestigios del cáliz; semillas negras, numerosas, de 2.2-3 $\mathrm{mm}$ de largo, 1-1.5 $\mathrm{mm}$ de ancho, elipsoides, regularmente comprimidas.

TIPO: México, Michoacán, mpio. Zinapécuaro, $1 \mathrm{~km}$ al NW de Laguna Larga, sobre el camino a Yerba Buena, Rzedowski 46282 (Holotipo: XAL; Isotipos: IEB, MEXU).

Material adicional examinado. Mpio. Pátzcuaro, parte alta del Cerro del Burro, cerca de Cuanajo, H. Díaz B. 1014 (MEXU); mpio. Huiramba, parte alta del cerro La Taza, H. Díaz B. y S. Zamudio R. 2623 (IEB); mpio. Zinapécuaro, alrededores de Laguna Larga, Los Azufres, H. Díaz B. 4681 (IEB, XAL); mpio. Santa Clara del Cobre, Cerro del Burro, J. M. Escobedo 868, 1399 (IEB, MEXU, XAL); mpio. Santa Clara del Cobre, Cerro del Burro, E. Pérez C. 48 y 270 (IEB); mpio. Queréndaro, Cañada del Real, cerca de San José de la Cumbre, J. S. Martínez 1310 (IEB, XAL); mpio. Ciudad Hidalgo, paraje El Pino, cerca de Huajúmbaro, J. S. Martínez 1450 (ENCB, IEB, XAL); mpio. Zinapécuaro, ladera SW del cerro San Andrés, S. Zamudio R. 5519 (IEB).

El epíteto específico de este nuevo taxon se deriva del tamaño de los sépalos, carácter que lo distingue del resto de las especies descritas con anterioridad para México (Janczewski, 1907; Coville y Britton, 1908). Se le conoce solamente del estado de Michoacán, donde habita en el bosque de Abies en cañadas pronunciadas, en altitudes que van de los 2500 a los 3200 m s.n.m. Se le encuentra en floración entre los meses de marzo a mayo.

La especie más cercanamente relacionada corresponde a $R$. pringlei Rose, que se distribuye en el Estado de México y en el Distrito Federal. A este respecto cabe comentar que en el estudio más reciente de las especies de Ribes del Valle de México realizado por Calderón de Rzedowski (2001), se considera a dicha especie como sinónimo de $R$. ciliatum.

Aunque algunos caracteres de $R$. grandisepalum y $R$. pringlei son variables, como el tamaño del hipantio, de los sépalos y de los pedicelos de las flores, y en ocasiones pueden solaparse los intervalos entre una especie y otra, dentro del conjunto se manifiestan como taxa separados. Por otra parte, $R$. pringlei se diferencia de $R$. ciliatum porque presenta frutos glandulares, así como otros rasgos que pueden apreciarse en el Cuadro 1 (Coville y Britton, 1908; Janczewski, 1907).

\section{AGRADECIMIENTOS}

Agradecemos al Dr. Francisco Lorea Hernández por la revisión crítica del manuscrito y la traducción de la diagnosis al latín y al Sr. Edmundo Saavedra por la estupenda ilustración del ejemplar. 
Durán y Avendaño: Una Nueva Especie de Ribes de Michoacán, México

Cuadro 1. Características diferenciales comparativas entre Ribes grandisepalum y especies afines.

\begin{tabular}{|c|c|c|c|c|c|}
\hline Caracteres & $\begin{array}{c}\text { Ribes } \\
\text { grandisepalum } \\
\text { C. Durán- } \\
\text { Espinosa \& } \\
\text { S. Avendaño }\end{array}$ & $\begin{array}{l}\text { Ribes pringlei } \\
\text { Rose }\end{array}$ & $\begin{array}{c}\text { Ribes ciliatum } \\
\text { Humb. \&Bonpl. } \\
\text { ex Roem. \& } \\
\text { Schult. }\end{array}$ & $\begin{array}{l}\text { Ribes affine } \\
\text { Kunth }\end{array}$ & $\begin{array}{c}\text { Ribes orizabae } \\
\text { Rose }\end{array}$ \\
\hline Haz de la hoja & $\begin{array}{l}\text { con pelos } \\
\text { glandulares } \\
\text { esparcidos }\end{array}$ & $\begin{array}{l}\text { con pelos } \\
\text { glandulares } \\
\text { esparcidos }\end{array}$ & $\begin{array}{l}\text { glanduloso a } \\
\text { glabrado }\end{array}$ & $\begin{array}{l}\text { escasamente } \\
\text { pubescente a } \\
\text { glabrado }\end{array}$ & glabro \\
\hline Envés de la hoja & $\begin{array}{l}\text { glanduloso- } \\
\text { pubescente } \\
\text { sobre las } \\
\text { venas }\end{array}$ & $\begin{array}{l}\text { glanduloso- } \\
\text { pubescente } \\
\text { sobre las } \\
\text { venas }\end{array}$ & $\begin{array}{l}\text { densamente } \\
\text { glanduloso- } \\
\text { pubescente }\end{array}$ & $\begin{array}{l}\text { pubescente } \\
\text { sobre las } \\
\text { venas }\end{array}$ & $\begin{array}{l}\text { glanduloso- } \\
\text { pubescente } \\
\text { sobre las } \\
\text { venas }\end{array}$ \\
\hline Pecíolos & $\begin{array}{l}\text { glanduloso- } \\
\text { pubescentes }\end{array}$ & $\begin{array}{l}\text { glanduloso- } \\
\text { pubescentes }\end{array}$ & $\begin{array}{l}\text { densamente } \\
\text { glanduloso- } \\
\text { pubescentes }\end{array}$ & pubescentes & $\begin{array}{l}\text { glanduloso- } \\
\text { pubescentes }\end{array}$ \\
\hline $\begin{array}{l}\text { Hipantio } \\
\quad \text { largo }(\mathrm{mm}) \\
\text { ancho }(\mathrm{mm})\end{array}$ & $\begin{array}{l}6.5-10 \\
4.5-8.5\end{array}$ & $\begin{array}{l}6-8 \\
3.5-4\end{array}$ & $4-5$ & $2-3.5$ & 4 \\
\hline $\begin{array}{l}\text { Sépalos } \\
\quad \text { largo (mm) } \\
\text { pubescencia }\end{array}$ & $\begin{array}{l}5.5-8.5 \\
\text { glanduloso- } \\
\text { pubescentes }\end{array}$ & $\begin{array}{l}\text { 4-6 } \\
\text { glanduloso- } \\
\text { pubescentes }\end{array}$ & $\begin{array}{l}4.5 \\
\text { pubescentes }\end{array}$ & $\begin{array}{l}2.5-4 \\
\text { pubescentes }\end{array}$ & $\begin{array}{l}3.8 \\
\text { pubescentes }\end{array}$ \\
\hline Color de las flores & $\begin{array}{l}\text { blanquecino a } \\
\text { rosado }\end{array}$ & $\begin{array}{l}\text { verde pálido } \\
\text { a púrpura }\end{array}$ & $\begin{array}{l}\text { blanco-verdo- } \\
\text { so, rosado o } \\
\text { crema }\end{array}$ & $\begin{array}{l}\text { blanco a ro- } \\
\text { sado }\end{array}$ & \\
\hline $\begin{array}{l}\text { Largo del pedice } \\
\text { lo }(\mathrm{mm})\end{array}$ & $7-17$ & $3-12$ & $4-7$ & $3-8$ & $5-8$ \\
\hline $\begin{array}{l}\text { Brácteas } \\
\text { largo }(\mathrm{mm}) \\
\text { ancho }(\mathrm{mm})\end{array}$ & $\begin{array}{l}7-26.5 \\
2-7.5\end{array}$ & $\begin{array}{l}5.5-9.5 \\
1.8-3\end{array}$ & $\begin{array}{l}4-9.2 \\
0.7-3.3\end{array}$ & $\begin{array}{l}4.5-15 \\
1-8\end{array}$ & $\begin{array}{l}6-7.5 \\
1.5-1.9\end{array}$ \\
\hline Ovario & glandular & glandular & glabro & glabro & glabro \\
\hline $\begin{array}{l}\text { Fruto } \\
\quad \text { indumento }\end{array}$ & glandular & glandular & glabro & glabro & glabro \\
\hline
\end{tabular}

\section{LITERATURA CITADA}

Berger, A. 1924. A taxonomic review of currants and gooseberries. New York Agric. Exp. Sta. Techn. Bull. 109: 1-118.

Coville, F. V. y N. L. Britton. 1908. Grossulariaceae. N. Amer. FI. 22: 193-225. 
Durán-Espinosa, C. 2001. Grossulariaceae. Flora de Veracruz 122: 1-15.

Janczewski, E. 1907. Monographie des groseillers, Ribes L. Mém. Soc. Phys. Genéve 35: 199-517.

Messinger, W., K. Hummer y A. Liston. 1999. Ribes (Grossulariaceae) phylogeny as indicated by restriction-site polymorphisms of PCR-amplified chloroplast DNA. PI. Syst. Evol. 217: 185195.

Poyarkova, A. I. 1939. Ribesoideae. In: Komarov, V. L. \& S. V. Yuzepchuk (eds.). Flora of the U.S.S.R. Israel Program for Scientific Translations, for the Smithsonian Institution and National Science Foundation. Washington, D.C., Jerusalem. pp. 175-208.

Rzedowski, G. C. de. 2001. Grossulariaceae. In: Rzedowski, G. C. de, J. Rzedowski y colaboradores. Flora fanerogámica del Valle de México. 2a. ed., Instituto de Ecología, A.C. y Comisión Nacional para el Conocimiento y Uso de la Biodiversidad. Pátzcuaro, Michoacán. pp. 215-219.

Sinnott, P. Q. 1985. A revision of Ribes L. subg. Grossularia (Mill.) Pers. sect. Grossularia (Mill.) Nutt. (Grossulariaceae) in North America. Rhodora 87: 189-286.

Sponberg, S. A. 1972. The genera of Saxifragaceae in the southeastern United States. J. Arnold Arbor. 53: 409-498. 